\title{
Beyond Survival: Policies for Academic Revitalization in An Uncertain Environment
}

\author{
THOMAS FLEMING*
}

\begin{abstract}
Confronted with growing public skepticism concerning the value of higher education, the spiralling costs of educational services and an overall mood of economic retrenchment and uncertainty, academic organizations face the need to develop policies to maintain their institutional health under increasingly difficult conditions. This discussion briefly describes educational developments since 1945 - particularly those factors which have contributed to the present climate of adversity - and explores how these historical forces have altered the complexion of university governance. Special attention is directed toward a review of proposals for academic revitalization found in recent literature and an examination of policies currently under consideration by senior administrators at universities in Western Canada.
\end{abstract}

\section{RÉSUMÉ}

Face à une méfiance accrue du puólic envers la qualité des études supérieures, aux coûts toujours croissants de l'éducation, et à un sentiment général de malaise économique, les organisations académiques se voient dans l'obligation d'élaborer des politiques destinées à maintenir leur vitalité en tant qu'institution, et cela dans des conditions de plus en plus difficiles. Cette présentation décrit brièvement les développements en éducation depuis 1945 - en particulier les facteurs qui ont contribués à la situation actuelle de confrontation - et étudie comment les forces historiques ont modifié l'aspect du gouvernement d'une université. L'attention est surtout portée sur une revue de la littérature récente traitant de propositions pour une revitalization académique, et un examen des politiques en état d'élaboration par les hauts administrateurs des université de l'ouest du Canada.

\footnotetext{
* Thomas Fleming has been Assistant to the President at the University of Victoria and Lecturer in Educational History at the same institution. Currently, he is a doctoral student in the Center for Policy Management at the University of Oregon.
} 


\section{INTRODUCTION}

Over the past five years, a growing body of scholarly writing has chronicled the problems confronting higher education in the next two decades and, in particular, the issue of academic revitalization in what is frequently described as a "no growth" period. Unfortunately, much of the literature on post-secondary institutional revitalization reveals little agreement on the effects of stabilization on current and future situations, and, while there appears to be a consensus that the legions of higher education are retreating from many of the educational frontiers of recent years, academic sentiment is divided as to whether the current falling back may be metaphorically more likened to Napoleon's chaotic retreat from Moscow or to the more recent and more orderly withdrawal of the Allies from Dunkirk. In either event, it is of small consequence since the history of education vividly documents not only the considerable survival skills of educational institutions at all levels but their remarkable tradition of resilience. The important question, therefore, is not whether higher learning will survive, but in what manner? In other words, can universities maintain their vitality in an increasingly stable and maturing situation? Can institutes of higher learning, in fact, sustain the spirit of vigorous investigation which has become their hallmark? Or will they, as the Carnegie Commission enquired, follow the tumultuous "boom and bust" cycle of the nineteenth century railroads? What policies will be required to ensure the institutional health of these organizations in future years and how can such policies be implemented? Clearly, these are considerable questions for all connected with higher education.

In attempting to address these issues, this paper will examine briefly in historical fashion the major forces which have contributed to the present climate of adversity, and how these forces have changed the nature of university governance. Special attention will be directed toward identifying the principal recommendations contained in the literature on academic renewal and amalgamating these suggestions with the proposals of senior administrators in Western Canada. The discussion will conclude with some general observations concerning academic progress in an unfavourable environment.

\section{SOME HISTORICAL CONSIDERATIONS}

To understand the present contra trend in higher education, it is necessary to examine the major social forces which have precipitated this condition. Two events are of particular note: the impetus toward egalitarianism which has characterized education since 1945 , and reached its apogee in the late 1960's; and, the emergence of a broadly-based expression of social reaction and disenchantment with education which has come to mark the 1970's.

The first movement, of course, was essentially democratic in character in that it sought to introduce the concept of equality of opportunity, the keystone of public schooling at other levels, into publicly-supported higher education. In retrospect, the success of this endeavour was assured through the gradual coalescence of a number of significant factors including a rapidly burgeoning school-age population; greater government support for institutions of higher learning and the students who attended them; a vigorous and expanding economy; and, an overall mood of rising public expectations with regard to education and other quality of life concerns. Central to this egalitarian impulse was the growing notion that educational institutions should accommodate greater numbers of 
students from increasingly diverse social and economic backgrounds. In short, new and sometimes onerous demands were made for the establishment of high quality academic programmes and facilities in the postwar years with the result that universities radically expanded their course offerings in the interests of consumer taste and relevance. And, while it can be argued that the massive growth in higher education during this period largely can be attributed to the broader sociological trend of delivering more public services to all elements of society, it should be noted that government sponsorship of higher education for all was chiefly predicated on the assumption that because higher learning had traditionally proved to be beneficial to a small segment of society, its universality would ensure even greater social and personal rewards. Few could forsee that the implementation of this untested proposition might prove deleterious and that the sideeffects of an emphasis on numbers would later haunt the groves of the academe.

The halcyon days of higher education were short-lived, however. In recent years, profound revisions in the political, social and economic matrix have resulted in the reduction of higher education from a preeminent place in the public mind to a position of receding significance. Although this reaction concerned education in general, much of the criticism was aimed directly at the universities. In the main, the bulk of the dissatisfaction centered on the belief that the public's faith in the higher educational enterprise had been misplaced, and that educators had exaggerated the reformist role that education could play in the amelioration of problems such as crime, poverty and unemployment. Additionally, spiralling costs for educational services, a downturned economy, changing public tastes for public services, and a shrinking labour market for graduates all conspired to elicit a mood of disenchantment, if not cynicism, among a loosely-formed coalition of social and political constituencies. The public mood now held that mammoth educational expenditures could no longer be justified either in terms of social betterment or investment in human capital and that the entire question of educational performance required investigation. In retrospect, one might sadly conclude that the democratic movement in higher education sowed the seeds of its own discontent. Like the Romans who extended the concept of municipal government to the reaches of the Empire some fifteen hundred years before, the universities attempted to accomplish "too much, too soon", and would be quickly compelled to consider both the limits and the wisdom of unchecked growth.

It should be remembered, however, that the recent reversal in academic fortunes has not only been rooted in external forces but owes appreciably to fundamental difficulties pertaining to questions of educational governance. To begin with, despite intensive enquiries into the economics of education in the last two decades, universities have operated without a conceptual basis which would assist them in understanding or predicting their behaviour or the behaviour of the higher education industry as a whole. While economists developed and applied the human capital theory to higher education in the early 1960's, this work focused attention on the user and not the supplier of educational services. In fact, this theory diverted attention from institutional questions and directed it toward private and social rates of return. While social scientists have developed organizational theories for the military and for business and industrial corporations, the extraordinary complexi: ties of university governance have defied any similar formulation. It is only of late that we have come to recognize that the differences between organizations in the public and private sectors far transcend the basic motives of profit-seeking, production and expansion which ordinarily characterize the latter enterprises, and that, to comprehend the unique 
composition of university administration, it is first necessary to come to terms with the medieval nature of the institution.

Two noteworthy observations confirm this latter shift in investigation. Sociologist James Coleman maintains that governance problems in higher education issue from the fact that institutions of higher learning have "lost the character of a community ... but ... retained the governing structure of a community, which neither takes corporate action nor is purposively organized toward a corporate goal." 1 In a similar view, organizationalist James March describes universities as "organized anarchies" in which goal setting processes are inconsistent, participation tends to be varied, and procedures for institutional survival are largely unclear and often haphazard. ${ }^{2}$ Simply, then, the management of such institutions has been complicated by more than a failure to identify and subsequently apply a "theory of the firm". The real difficulty is grounded in the unmanageability of these archaic administrative forms. Furthermore, the incapacity on the part of these institutions to perceive the manner in which an organization must relate to itself and to its environment has only added to the university's undoing. Thus, unfettered by the notion of longterm market considerations which constrain the activities of many organizations, universities drifted freely on the heady and expansionary tide of the 1960's.

In a larger sense, the tendency toward overbuilding which infected academic institutions during this time was rooted in history. As inheritors of the Enlightenment and Positivist thought of the eighteenth and nineteenth centuries, North Americans have persistently and almost unquestioningly accepted the doctrines of optimism, growth and progress. That these philosophic and social perspectives came to dominate conventional thinking in the affluent postwar years is no surprise nor is it difficult to reconstruct why universities were swept along by the notion that "nothing succeeds like excess." Given the facts that educational leadership is usually only of modest significance in directing the course of the organization, either in the short- or long-term, and that means to evaluate success are normally ambiguous in such organizations, it is not difficult to understand why senior administrators succumbed to the spirit of the age.

In a more practical sense, the effectiveness of university governance traditionally has been impaired by difficulties in a number of key administrative functions, particularly with respect to management support systems. For the most part, institutions have been plagued over time with major deficiencies in such critical areas as planning, policy making and resource allocation. Looking backward, it is apparent that activities in a variety of areas including programme and physical plant development, admission procedures, the recruitment and promotion of instructional personnel, and budgeting, to mention a few, were frequently conceived in terms which would be judged today as amateurish, if not primitive. Management problems in higher education have been further aggravated by the underdeveloped nature of institutional research and analysis units and by the general reluctance of academicians to solicit the expertise of professional administrators or to utilize modern management techniques.

\section{THE CHANGING NATURE OF UNIVERSITY GOVERNANCE}

By the early 1970's, the need for improved planning in higher education was obvious. Internal factors, including the decline in full-time enrollments, changing patterns of 
student attendance and the rapidly rising costs of goods and services, signalled the beginning of a period of financial uncertainty. Already beset by these internal difficulties, the task of managing universities was exacerbated by such external pressures as widespread community demand for more stringent measures of accountability and performance and by pessimistic forecasts for economic growth. Collectively, and within a brief span of time, these forces provoked two significant changes in the administration of higher education. First, the concept of institutional autonomy which had long been husbanded by the universities was successfully challenged by ministerial agencies with the result that the power to determine major developments at publicly funded institutions has been increasingly centralized at the state or provincial level. Thus, decision making powers involving the allocation of resources, programme approval or capital expenditures no longer solely reside with university authorities. In recent years, these government councils have proliferated in both the United States and Canada, and can be expected to play a major role in the direction of higher learning over the next two decades. For example, in 1960 only six states had provided for superordinate bodies to coordinate statewide systems; a decade later, twenty-seven states had issued discretionary powers to off-campus boards to make decisions on matters such as capital spending, tuition fees, programme rationalization and physical plant siting.

The effects of the establishment of similar boards at the provincial level in Canada are well-known and do not require documentation. Finally, it should be noted that, while the establishment of these boards has been effective in terms of formal planning and the rationalization of resources, these new governing structures have precipitated some additional concerns for university management. Notably, many of the planning and management resources of academic administrators have been exhausted in attempting to fulfil requests for information from staff members of these executive committees. Consequently, the time necessary for programme formulation and development, not to mention the plethora of other management duties, has been seriously undercut. This imposition on the time and energies of top administrators will continue to detract from the capabilities of institutions to confront the important issues of renewal in an unfavourable climate.

The second major alteration in academic governance involves a considerable shift in decision making authority within universities. Government intervention and the contraction of public support have led to a mood of increased introspection in the university community and, as a result, greater attention has been directed toward the refinement of management practices, planning techniques and the identification of institutional objectives and mission. This new emphasis not only suggests that universities are moving closer to industrial and corporate management models but that administrators and faculty alike now realize the need to convince the public of their efficiency and utility. Certainly, in the recent past, the locus of decisional power appears to have been transferred from faculty bodies to their elected or appointed representatives such as department chairmen, deans and vice-presidents. While this movement away from the traditional mode of collegial decision making does not mean that the influence of faculty has been appreciably diminished, it does, however, imply that faculty are now more prepared to accept strong leadership in difficult times. Clearly, academic administrators have assumed a greater presence inside and outside the university and appear to be more instrumental in determining institutional policies and to exhibit greater discretionary authority in the allocation of scarce resources. Concomitant with this support is the obvious expectation on the part of 
faculty that these administrative officers will be persuasive and successful advocates of the need for increased funding for higher education. Stated somewhat differently, administrators have been charged with the difficult task of mediating between the interests of government and the public on one side and the universities on the other.

\section{CANADIAN UNIVERSITIES IN A "NO GROWTH" ERA}

Apart from the preceding considerations which tend to be global in nature, efforts at institutional revitalization in Canada must address two overriding problems in the coming years: the changing demographics of student and faculty populations; and the issue of static or shrinking resources on academic progress. First, it is generally anticipated that demographic developments will precipitate a serious reduction in the number of full-time students in the early 1980's, since the size of the eighteen to twenty-four year age group, which normally accounts for approximately 80 percent of full-time enrollment in higher education, will begin to decline in 1982, from a high point of 3.3 million in that year to 2.6 million in $1992 .^{3}$ A recent forecast suggests that, if the participation rate of this age group remains stable, the number of full-time students will likely decline by approximately 22 percent within the decade. ${ }^{4}$ Further long-term projections estimate that total student enrollment in universities will recover to present levels by the year 2000 .

The circumstances surrounding faculty populations are markedly different. In order to meet the rising demand for higher education in the 1960's and early 1970's, the number of full-time equivalent university teachers in Canada increased from approximately ten thousand to thirty-seven thousand in the period 1962-63 to 1974-75. Not only was this growth in the number of instructional personnel significant in itself, but of perhaps greater importance was the fact that the nation's professoriate was particularly young. In 1975-76, the vast majority ( 84 percent) were between the ages of thirty and fifty-four; and more than 90 percent were younger than age fifty-five. ${ }^{6}$ The implications of these statistics are obvious and manifold: the availability of replacement positions, which depend on retirement, mortality and mobility, will continue to be low - approximately 350 openings per year over the next five years; ${ }^{7}$ a profound imbalance will exist with respect to the number of available positions and the number of qualified candidates seeking employment Canadian universities are presently producing approximately sixteen hundred to eighteen hundred Ph.D.'s annually; the failure to provide young scholars with the opportunity for academic careers will deprive universities of an important regenerative resource and alternative employment opportunities will become a crucial issue in higher education - moreover, there are undoubtedly some negative effects to be considered in relation to the research productivity of an ageing body of scholars; the youthfulness of the current teaching body and their expected progress through academic ranks will inevitably lead to a greater number of faculty at the upper end of the salary scale - given the likelihood that resources will stabilize, this will mean that ultimately a greater percentage of institutional budgets will be earmarked for instructional salaries; the retirement of large numbers of academicians in the last decade of this century will place immense pressures on pension funds; and, lastly, by the 1990's there will be a new demand for teachers to the point where a shortage may exist. Thus, faculty populations will remain stable over these years unless institutions embark on some deliberate strategies to terminate positions or to create positions through turnovers. 
Unfortunately, universities will receive little assistance in their efforts to combat the difficulties attendant with changing demographics. Government policies of economic retrenchment established of late will likely be extended far into the future. At the provincial level, most governments have begun to curtail the growth rate of expenditures for higher education and will continue to do so. Federal government grants will likely remain fixed or will decline slightly in constant dollars, as will revenues from other sources. In fact, austerity in federal funding will continue to have a serious impact on research. Since 1969 , there has been only modest change in federal support for research and development which has meant a real decline in recent years. Lastly, it may be anticipated that while tuition fees will rise, perhaps according to some indexed formula, the revenue provided by this source will only constitute a small percentage of any institution's net operating cost.

\section{POLICIES FOR ACADEMIC REVITALIZATION}

Revitalization efforts divide into two essential types: those that involve programme renewal or curricular modifications for a changing clientele; and those that are primarily designed to promote intellectual vitality among personnel. An interrelationship exists in that mechanisms for programme renewal are generally held to be the result of individual or group activities in a vigorous intellectual climate, although the presence of creative individuals in a favourable environment does not necessarily ensure ongoing or timely programme developments. ${ }^{8}$ Given the acceptance of this premise, it appears to be more fruitful to examine in greater depth strategies which attempt to foster professional growth. In fact, it is interesting to note that the proposals for academic progress made by both scholars and administrators are overwhelmingly directed toward the latter approach.

Six major policies are commonly offered as means to promote institutional renewal through the regeneration of the teaching/research force. Each of these involve to some degree either the reduction, replacement of exchange of manpower:

\section{(1) Termination of Position}

In general, two options can be considered with respect to the termination of instructional positions. At the time of a faculty member's resignation, dismissal or death, a decision can be made to replace the individual or, alternatively, to terminate the position. If the latter course of action is chosen, the savings which result can be applied toward reducing an organization's overall operating budget or redeployed in other areas of the institution.

For a number of reasons, however, the termination of a position usually presents some difficult problems. To begin with, a decision of this nature typically involves reducing in whole or in part a department's programme offerings in specialized areas depending on the level at which the appointment was made and the responsibility and scope of assignment attendant with it. While it may be justifiable for administrators to deny requests for continued staffing in areas of declining student enrolment, it is an entirely different decision - and one that is less defensible - to reduce a department's instructional component through the termination of a position (or positions) and thereby risk its potential attractiveness to students. Stated simply, ordinarily it is not possible to economize by refusing appointments in fields of study where student subscription is satisfactory. Rather, it is a more common occurrence to reduce the level at which appointments are 
made in the interest of cost-saving. In other words, vacant positions previously held by senior faculty are "filled" by junior members or other appointments, often on an interim (non-tenured) or adjunct basis in the interest of lessening an institution's ongoing financial commitment. As might be expected, such attempts to pare operating costs are strongly resisted by faculty associations on and off-campus who wish to protect the career paths (salary structures) and security of the professoriate.

Recent discussions of retrenchment in higher education have considered the introduction of redundancy provisions in faculty contracts to facilitate the elimination of surplus staff in instructional areas where workloads or enrollments are diminishing. It is anticipated that this option will involve high costs to academic organization and will provoke similar levels of faculty disapproval. Unfortunately, the literature which proposes such a course of action fails to document cases where this policy has been implemented.

\section{(2) Early Retirement}

Without a doubt, this is the most frequently discussed suggestion for institutional renewal and one that embodies a certain superficial appeal since it readily appears to promote the appointment of younger faculty members. However, the success of this policy as a mechanism for renewal has been questionable to date. Above all, it must be remembered that early retirement schemes are reliant on the voluntary participation of faculty. If a university arbitrarily reduces a tenured faculty member's term of employment the individual could rightly claim that his contract had been violated. In other words, for an early retirement plan to function effectively it must not only receive the endorsement of faculty but must feature sufficient incentives to induce participation. The current uncertain economic climate and inflationary costs, no doubt, militate against its success. For example, if a faculty member should decide to retire at sixty-two rather than at sixty-five years of age, he would undoubtedly face the following penalties: reduced social security benefits: a retirement fund which has been shortened by three years' contributions; and, a decrease in the annual yield of this fund since his life expentancy has been extended by three years. Unless institutions are prepared to support "encouraged" retirement plans which do not penalize faculty, the potential of this approach will be considerably discounted.

Both Dartmouth and Stanford Universities have developed some worthwhile variations on the concept of early retirement. Dartmouth's "Flexible Retirement Options" allows faculty to retire early with full benefits but reduces the individual's base salary in his final years with the institution. ${ }^{9}$ At Stanford, incentives have been developed to promote the retirement of less productive older faculty who have reached the age of sixty and who have had at least fifteen years of service in the university. Under this plan, faculty members are offered substantial bonuses to retire and these bonuses are larger where the salary is smaller. Because Stanford operates on the basis of differential faculty salaries, with high salaries awarded for achievement, the incentive to retire early is most advantageous to the less productive. $^{10}$

It should be noted that aside from the financial exigencies which prohibit early retirement in many cases, there is a growing reaction, at least in the United States, toward the practice of forced retirement at age sixty-five. In fact, a bill has recently passed the United States House of Representatives to abolish age-based retirement in the public service and to raise the retirement age in private industry to seventy. One can assume that this legislation reflects the sentiments of a fairly broad constituency and that early retirement pro- 
grammes may therefore encounter additional resistance from some hithertofore unexpected quarters. In short, the psychological costs associated with early retirement - which will be no doubt appreciable in some cases - may constitute a serious source of resistance and one not easily overcome by the promise of economic inducements.

\section{(3) Faculty Exchange}

Traditionally, there has been little need for any type of formal faculty exchange programmes. Operating budgets in the past ordinarily have permitted universities to make appointments according to expanding areas of study, growing student demand or other institutional circumstances. Whatever "exchanges" have occurred have been implemented in a largely informal and uncoordinated fashion such as summer session or visiting lecturer appointments. In other words, arrangements have been rarely, if ever, of a quid pro quo nature. An individual's decision to teach at another institution on a temporary basis did not involve the "trading" of similar or otherwise equal talents by the universities concerned.

Current conditions, however, compel a serious examination of the notion of faculty exchange as a means of promoting academic revitalization. The benefits which may be derived from such a scheme are obvious. First, it affords universities an opportunity to trade faculty members of differing teaching research and professional skills in the interest of sustaining a vigorous scholarly climate and providing expertise in certain specialized areas without the costs attendant with long-term institutional commitments. Second, exchange programmes could avoid some of the thornier problems associated with termination and early retirement. And, finally, such measures could serve to enhance professional development by allowing faculty a greater facility for interaction with their colleagues in other universities.

Despite these unquestionable advantages, a number of difficulties exist. To begin with, because of the geographical enormity of the country, the costs of relocating faculty and their families may be substantial in some cases. Also, changes in environment may prove disruptive to various aspects of family life, particularly to the schooling of children and the occupation or career of a spouse. In brief, the resettlement of families may involve financial and social expenses not normally considered by existing institutional policies (clearly, such costs are reduced in instances where faculty members are single or without children). Furthermore, problems with respect to research facilities may arise in areas where laboratory space, equipment, or other special requirements are necessary for the work of an exchange scholar. For example, if an instructor in the humanities is exchanged for one in the biological sciences the transaction may overburden the resources of the department receiving the scientist. Over time, such "inequalities" could result in the limitation of exchanges to faculty within comparable fields of study.

In any event, careful organization and ccordination on the part of both faculty and administrators will be necessary to ensure the effectiveness of exchange programmes. This investment of time and energy, however, appears modest compared to the returns which may be expected. Given that sufficient "lead-time" is made available for administrative purposes, programmes of this type could provide institutions with a much-needed sense of flexibility. Exchanges could be undertaken on a short-term (a few weeks) or longterm (a few months or a year) basis, and some form of "scorekeeping" could be developed, either internally or externally, to monitor the difficulties and costs in the exchange or matching of talents. 


\section{Thomas Fleming}

\section{(4) Other Types of Appointments}

In an effort to promote flexibility, economy and renewal, a number of measures are being presently entertained which involve new or alternative types of appointments. Beyond the apparent and widespread attempts to replace some senior academics with junior appointments for professional and fiscal reasons, much attention has been directed of late toward the greater use of short-term positions in the hope of alleviating programme deficiencies or the instructional vacuums created by study leaves. At the same time, considerable interest has been focused on breaking away from the traditional pattern of full-time, full-year academic appointments. In recent years, institutions across the country have been staffing a variety of programmes with partial-year and part-time instructors. However, the substitution of temporary for full-time staff poses certain problems. Local and national faculty associations are generally opposed to changes of this nature for obvious reasons and resist institutional efforts accordingly. Similarly, part-time instructors are becoming better organized and are negotiating collectively for increased job security, improved employment benefits and more clearly defined conditions of work (specifically, with respect to the development of guidelines for reappointment and termination). As a result, much of the flexibility once enjoyed by universities in the hiring of sessional instructors has disappeared, thus undercutting the discretionary power of academic administrators to appoint part-time staff as special needs arise.

The use of temporary appointments as a cost saving measure also has serious implications with regard to the nature of professional activities, and ultimately, to the productivity of the academic enterprise. Quite clearly, organizational expectations concerning faculty output in terms of research, publication, other forms of scholarly endeavor and institutional commitment differ markedly between full and part-time appointments. In general, temporary instructors are not expected to engage in research and writing or to participate in organizational affairs simply because their appointments are not of a continuing nature and the criteria for their appointment to permanent positions are often unclear. Consequently, the widespread use of such faculty for extended periods of time may undermine to some degree an institution's research capacity by emphasizing teaching responsibilities at the expense of scholarly investigation.

In the interest of revitalization, a variety of other suggestions have been made concerning the special use of personnel, including: the appointment of larger numbers of senior academic administrators from outside the institution to promote organizational vitality and fresh perspectives on institutional activities; the reallocation (or division) of faculty assignments to take fuller advantage of individual talents by classifying some positions as predominantly instructional in character and others as research-oriented; increasing the number of adjunct or visiting professorships or other non-tenured positions to recruit capable individuals who otherwise might not qualify for long-term appointments; and, the creation and upgrading of research associate positions to attract and retain outstanding post-doctoral students in all academic and professional faculties. Again, it can be anticipated that faculty associations will resist these kinds of institutional efforts to address the issue of revitalization.

\section{(5) Revisions to Tenure and Promotion Procedures}

Various revisions to tenure and promotion procedures have been entertained in recent years by those who study academic organizations. Concerns with academic productivity 


\section{Beyond Survival: Policies for Academic Revitalization}

and accountability have led to some discussion of the abolition of tenure. In its place, it has been suggested that universities should make all appointments on a definite term basis and renew contracts according to faculty productivity. Of course, such suggestions have encountered strong opposition from faculty organizations and individual members who view this notion as a serious threat to job security and academic freedom. The force of precedent in granting tenure and the high level of organized resistance to this idea makes it unlikely that a change of this order could be implemented in the foreseeable future.

Some thought has also been directed toward lengthening pre-tenure probationary periods and delaying promotion through the ranks. Although policies of this nature suggest some obvious benefits to universities in terms of economy, the reduced rate of promotion will accelerate in some cases the out-migration of scholars, notably in the sciences and other applied areas where faculty members can readily obtain career positions in industry and government. Additionally, adjustments to tenure and promotion rates are ordinarily subject to negotiations with faculty associations. Simply, then, while this proposal is cited on occasion as a possible solution to the problem of renewal, its implications have yet to be seriously investigated.

\section{(6) Retraining}

Because of changing market conditions, it has been frequently suggested that universities develop some innovative forms of professional development other than the normal range of leaves, secondments and exchanges which usually only serve to bolster the expertise of faculty in their specialized areas of activity. In the main, it is proposed that faculty can be retrained to assume new responsibilities in other areas related to their discipline. This retraining could be effected during study leaves and could serve to enhance renewal in that it would permit academic staff to operate in fields of current interest. At the same time, it could facilitate a lateral shift of surplus staff within an institution and might have an additional impact of relocating staff who are presently miscast in their roles. (For example, it could serve as a useful mechanism to develop ineffective instructional or research staff into lower level academic administrators, although there is no guarantee that such individuals would perform satisfactorily in this latter role.)

It should be noted, however, that beside the obvious need to secure faculty approval for this idea, several other implications should be examined. First, the notion of retraining is not as simple as it appears in that it may require extensive effort on the part of individuals concerned. Moreover, there may be considerable levels of psychological resistance to a change of this order. Second, research grants and other forms of support are usually awarded to faculty working within their area of specialization, thus raising the question of who will fund retraining programmes which, in all likelihood, will be expensive. Third, a use of sabbaticals for retraining clearly suggests that the participants will be engaged in study rather than research. This commitment will have a definite impact on promotion policies since research and publication generally comprise the basis for academic advancement and tenure. In short, it can be anticipated that the implementation of retraining programmes may have a profound ripple effect throughout the system.

Aside from policies which directly confront the issue of renewal through academic change, several other proposals can be entertained which relate to institutional revitalization and survival in a broader sense, and thus merit at least brief attention. Invariably, these suggestions involve the "selling" of education to some degree. The most popular 
recommendation in this respect is for universities to broaden their admissions policies to include a wider clientele and, particularly, to develop more fully markets in adult and continuing education. To complement the search for new users of educational services, it has been proposed that institutions modify their scheduling to offer full- and minicourses at times of peak demand. Additionally, certain degree programmes could be developed which would more appropriately serve the needs of business, industry, and government. Currently, both the corporate sector and government expend appreciable resources retraining university graduates. Naturally, increased external interest in more practical kinds of training raises concerns within institutions that universities are being engulfed by a wave of "creeping vocationalism." In fact, one can foresee future conflicts arising between the development of programmes responsive to new social needs and more traditional programmes which emphasize intellectual integrity and academic excellence.

Another consideration which is frequently but unduly overlooked is the matter of student attrition. Because institutional interest has concentrated on changing population trends, little attention has been directed to date toward maintaining student participation by reducing drop-out rates, which are sizeable in many universities. One can confidently predict a greater scrutiny of attrition rates by university management across the country in the immediate future. After all, attrition does not necessarily denote student failure. It may more accurately reflect student dissatisfaction with educational services and products.

\section{CONCLUSION}

In reviewing the current state of knowledge with respect to institutional renewal, it is apparent that there are no easy answers to the difficult problems of revitalization. A major impediment to more rational policy and decision making in this area involves the lack of an appropriate information base which could yield data on such important questions as: what types of students are enrolled in higher education and how are they distributed throughout disciplines and programmes; what effects do faculty and programmes have on these types of students; what relationships exist between faculty expertise, programme development and the eventual career success of students; who drops out, and why, and what do they do afterwards; and what kinds of academic innovations are most profitable for faculty and students? Without a better understanding of these issues through improved institutional analysis, the process of renewal will remain ad hoc at best.

What is more clear, however, is that the success of revitalization efforts depends largely on administrative leadership. While faculty support and participation is essential, the fine mix of rewards and sanctions and the overall climate for renewal can only be generated by top management. It is at this level that the broader issues can be identified, institutional consciousness can be heightened and reform measures can be imposed.

It is obvious the government policies of retrenchment will continue and that the costs of goods and services will escalate annually. Economic constraints will shape much of the activity in all areas of higher education, and, while institutions must endure certain uncontrollable expenses such as utilities, one can anticipate the advent of more stringent measures with regard to salaries and other operating costs. The adverse economic situation will undoubtedly impact heavily upon specific areas in higher education such as research and graduate study. Moreover, it will prompt universities to direct their attention to local and 
115 Beyond Survival: Policies for Academic Revitalization

regional rather than national needs. In all, the coming decade will likely be a time of difficulty for university administrators, who may be forced to suffer, like Shakespeare's characters, "the winter of their discontent" before this term of trial will pass.

\section{FOOTNOTES}

1 James S. Coleman, "The University and Society's New Demands", in Carl Kaysen (Ed.), Content and Context (New York: McGraw-Hill), 1973, p. 368.

2 Michael D. Cohen and James G. March, Leadership and Ambiquity - The American College President (San Francisco: McGraw-Hill), 1974, p. 3.

3 Max von Zur-Muehlen, "The New 'Crisis' of Canadian Universities" (Ottawa: Statistics Canada), Third draft, January 4,1977, p. 6.

4 Z. Zsigmond, "Future Trends in Canadian Education", Advance Statistics of Education 1976-77 (Ottawa: Statistics Canada), August 1976.

5 von Zur-Muehlen, "The New 'Crisis"', p. 6.

6 Ibid., p. 8.

7 Ibid.

8 This discussion of the relationship between policies for programme and professional renewal owes much to Brian Tinker, Vice-President of the University of Regina.

9 John G. Kemeny, "The University in a Steady State", Daedalus, Vol. 104, No. 1, Winter 1975, p. 93.

10 Sally and Richard Zeckhauser, "Encouraging Improved Performance in Higher Education", Daedalus, Vol, 104, No. 1, Winter, 1975, p. 106. 